\title{
Experiências artísticas e estéticas na aprendizagem e desenvolvimento das crianças em idade pré-escolar: contribuições da pedagogia histórico-crítica e da psicologia histórico-cultural
}

\author{
Artistic and aesthetic experiences in the learning and development \\ of pre-school children: contributions from the historical-critical \\ pedagogy and historical-cultural psychology
}

Experiencias artísticas y estéticas en el aprendizaje y desarrollo de niños en edad preescolar: aportes de la pedagogía histórico-crítica y psicología histórico-cultural

\author{
Poliana Hreczynski Ribeiro' \\ https://orcid.org/0000-0002-9389-7931 \\ Heloisa Toshie Irie Saito² \\ https://orcid.org/0000-0003-1061-5933 \\ Marcos Vinicius Francisco 3 \\ https://orcid.org/0000-0002-54I0-2374
}

Resumo: Nesta investigação, assumiu-se como objetivo central compreender as experiências artísticas e estéticas para a aprendizagem e o desenvolvimento das crianças em idade pré-escolar a partir de um ensaio crítico e contextualizado de caráter bibliográfico. Ou seja, o delineamento metodológico contemplou o diálogo com leituras clássicas e atuais, tendo como referenciais a pedagogia histórico-crítica e a psicologia históricocultural que, por sua vez, permitem (re)pensar os processos de ensino e de aprendizagem com vistas à uma formação humana, sensível e emancipatória. Os resultados revelaram que o processo de ensino e aprendizagem precisa ser planejado e sistematizado a partir de intencionalidades mais amplas, com ênfase nas dimensões gnosiológica, ontológica e teleológica, considerando a relevância do/a professor/a na organização das práticas

\footnotetext{
${ }^{1}$ Graduada em Pedagogia pela Universidade Estadual de Maringá (UEM). Mestranda junto ao Programa de Pósgraduação em Educação (PPE/UEM). E-mail: pollyannahre@hotmail.com

${ }^{2}$ Doutora em Educação pela Universidade de São Paulo (USP). Professora do Departamento de Teoria e Prática da Educação (DTP) e do Programa de Pós-graduação em Educação da Universidade Estadual de Maringá (PPE/UEM). E-mail: htisaito@uem.br

${ }^{3}$ Doutor em Educação pela Universidade Estadual Paulista (Unesp), campus de Presidente Prudente-SP. Professor do Departamento de Ciências do Movimento Humano (DMO) e do Programa de Pós-graduação em Educação da Universidade Estadual de Maringá (PPE/UEM). E-mail: mvfrancisco@uem.br
} 
Experiências artísticas e estéticas na aprendizagem e desenvolvimento das crianças em idade pré-escolar...

pedagógicas de modo a favorecer a apropriação e a objetivação dos conhecimentos artísticos por parte dos/as alunos/as inseridos/as nas instituições formativas de Educação Infantil.

Palavras-chave: Conhecimentos artísticos. Estética. Formação Humana.

Abstract: In this investigation, it was assumed as the main objective understanding the artistic and aesthetic experiences for the learning and development of preschool children starting from a critical and contextualized bibliographic essay. In other words, the methodological design contemplated the dialogue with classical and current readings, having as a reference the historical-critical pedagogy and historical-cultural psychology, which in turn, allows (re)thinking the teaching and learning processes aiming at a sensitive and emancipatory human educational training. The results revealed that the teaching and learning process must be planned and systematized from broader intentions, with emphasis on the gnosiological, ontological and teleological dimensions, considering the relevance of the teacher in the organization of pedagogical practices in order to favor the appropriation and objectification of artistic knowledge on the behalf of the students inserted in the formative institutions of Early Childhood Education.

Keywords: Artistic knowledge. Aesthetics. Human educational training.

Resumen: En esta pesquisa, el objetivo principal fue comprender las experiencias artísticas y estéticas para el aprendizaje y desarrollo de niños en edad preescolar, desde un ensayo crítico y contextualizado de carácter bibliográfico. Es decir, el diseño metodológico contempló el diálogo con las lecturas clásicas y actuales, teniendo como referencias la pedagogía histórico-crítica y psicología histórico-cultural, que permiten (re) pensar los procesos de enseñanza y aprendizaje con miras a una formación humana, sensible y emancipadora. Los resultados revelaron la necesidad de planificar y sistematizar el proceso de enseñanza y aprendizaje con base en intencionalidades más amplias, con foco en las dimensiones gnosiológica, ontológica y teleológica, teniendo en cuenta la relevancia del docente en la organización de las prácticas pedagógicas con el fin de favorecer la apropiación y objetivación de los conocimientos artísticos y estéticos por parte de los estudiantes que constituyen las instituciones educativas de Educación Infantil.

Palabras-clave: Conocimientos artísticos. Estética. Formación humana.

\section{Introdução}

A motivação para a realização deste artigo originou-se de pesquisas e leituras acerca do processo de ensino, aprendizagem e desenvolvimento dos seres humanos e da importância das instituições formativas para viabilizar tal processo, tendo como amparo os estudos clássicos e contemporâneos da pedagogia histórico-crítica e da psicologia histórico-cultural.

Mori (2016, p. 24) afirma que muitas pesquisas legatárias dessas teorias acabam não considerando a sua base epistemológica, sendo o materialismo histórico-dialético “[...] desconsiderado na delimitação do problema e na definição do problema e na definição dos instrumentos de pesquisa e, logicamente, da análise dos dados”. A partir do delineamento metodológico deste ensaio crítico e uma vez contextualizado seu cunho bibliográfico, tal dimensão foi considerada como condição sine qua non, sobretudo na sistematização dos dados aqui apresentados a fim de garantir a síntese das múltiplas determinações que compõem o objeto de estudo em tela.

Conforme Gil (2002, p. 45), “a principal vantagem da pesquisa bibliográfica reside no fato de permitir ao investigador a cobertura de uma gama de fenômenos muito mais ampla do que aquela que poderia pesquisar diretamente". No caso deste ensaio crítico, devidamente contextualizado em seu cunho bibliográfico, alguns procedimentos foram adotados, quais sejam: 
- elegeram-se literaturas clássicas, consideradas essenciais para a compreensão do desenvolvimento humano no diálogo entre a pedagogia histórico-crítica e a psicologia histórico-cultural;

- selecionaram-se literaturas contemporâneas que possuem como base teórico-epistemológica e ontológica a pedagogia histórico-crítica e a psicologia histórico-cultural, as quais deveriam versar sobre a compreensão das experiências artísticas e estéticas nas instituições formativas de Educação Infantil. As dissertações e teses foram identificadas na Base Digital de Teses e Dissertações (BDTD), ao passo que os livros e artigos são de pesquisadores/as considerados/as referências nacionais, com forte inserção na Pós-graduação em Educação e Psicologia no Brasil ao longo das últimas décadas.

Nessa perspectiva, os estudos clássicos acerca do desenvolvimento humano contemplam as obras de Vygotski (1991), Vigotski (2003; 2009; 2010), Vigotskii (2016), Leontiev (1998; 2016) e Lunatcharski (1988). Somam-se a estas obras, os/as seguintes autores/as contemporâneos/as: Mello (1999), Martins (2006), Oliveira (2010), Saviani (2013), Stein (2014), Magalhães (20I4), Lazaretti (2016), Saito e Oliveira (2018), dentre outros.

Para os/as autores/as supracitados/as que assumem como base teórica a pedagogia históricocrítica e a psicologia histórico-cultural, a idade pré-escolar vai dos três aos seis anos de idade. Contudo, uma especificidade do contexto brasileiro é que tal subdivisão modificou-se a partir do I Plano Nacional de Educação - PNE (200I/20I0), aprovado pela Lei n ${ }^{\circ} 10.172$ de 200I, e que apresenta, em sua segunda meta, a perspectiva de "universalizar o ensino fundamental de nove anos para toda população de 6 a 14 anos” (BRASIL, 200I). Em virtude dessa alteração, o Ensino Fundamental deixou de ter oito anos e passou a ser ministrado em nove anos, com o ingresso das crianças a partir dos seis anos de idade, antes atendidas pela pré-escola (MARTINS; ARCE, 20I0).

Ao longo de dez anos, período de implementação dessa meta, houve a promulgação das Leis Federais $\mathrm{n}^{\circ}$. II.II4 de 2005, e $\mathrm{n}^{\circ}$. II.274 de 2006, as quais instituíram a obrigatoriedade do Ensino Fundamental com duração de nove anos, por meio do ingresso de crianças aos seis anos de idade (BRASIL, 2005; 2006), o que possibilitou o êxito da Meta 2 prevista no antigo PNE.

Posteriormente, a Lei $n^{\circ}$. 12.796 de 2013 reafirmou essa determinação, sobretudo ao alterar a redação da Lei de Diretrizes e Bases da Educação Nacional - LDB (1996) nº 9.394 de 1996 -, ampliando a duração do Ensino Fundamental para nove anos, com início aos seis anos de idade completos ou a completar até o início do ano letivo nessa etapa educacional. Soma-se a esse dispositivo - Art. 30, inciso segundo, o qual estabelece o atendimento a "pré-escolas, para as crianças de 4 (quatro) a 5 (cinco) anos de idade" (BRASIL, 20I3), orientando, inclusive, como deve ser estruturado o trabalho educativo com crianças em idade pré-escolar focado em instituições formativas de Educação Infantil que atendem a pré-escola (4 e 5 anos de idade).

Olhar de professor, Ponta Grossa, v. 24, p. I-17, e-17622.079, 2021.

Disponível em <https://revistas2.uepg.br/index.php/olhardeprofessor> 
Experiências artísticas e estéticas na aprendizagem e desenvolvimento das crianças em idade pré-escolar...

Isto posto, ao referir-se à idade pré-escolar, convém destacar a atividade principal/dominante que norteia o desenvolvimento infantil, ou seja, a brincadeira de papéis sociais, cujo início encontra-se na transição das ações e manipulações dos objetos durante a primeira infância (0-3 anos).

Abrantes e Eidt (2019, p. 22) complementam que as mudanças qualitativas inerentes à primeira infância corroboram a crise dos três anos. Ela constitui "a unidade contraditória entre a busca de autonomia da criança, na situação em que procura realizar atividades da vida diária com independência, e os limites operacionais para a sua realização". A busca por autonomia, seguida da expectativa de "integrar-se ao mundo adulto caracteriza o início da dominância da atividade de brincadeira de papéis".

A brincadeira de papéis sociais permite à criança vislumbrar novas possibilidades, ainda que no âmbito imaginário, de vincular-se à prática social materializada nas profissões e ocupações sociais, oriundas das relações contraditórias entre homem e natureza. Em síntese, por seu intermédio as crianças terão contato com o trabalho adulto em suas distintas possibilidades.

Sob este viés, afirma-se que "o critério na transição de um estágio para o outro é precisamente a mudança do tipo principal de atividade na relação dominante da criança com a realidade" (LEONTIEV, 2016, p. 64), ou seja, a transição entre os estágios reside na mudança da atividade principal/dominante:

[...] embora os estágios do desenvolvimento também se desdobrem ao longo do tempo de certa forma, seus limites de idade, todavia, dependem de seu conteúdo e este, por sua vez, é governado pelas condições históricas concretas nas quais está ocorrendo o desenvolvimento da criança. Assim, não é a idade da criança que determina, enquanto tal, o conteúdo do estágio de desenvolvimento, mas, pelo contrário, a idade da passagem de um estágio a outro que depende do seu conteúdo e que muda com as condições sócio-históricas (LEONTIEV, 2016, p. 65-66).

Leontiev (2016) esclarece que é preciso pensar nas atividades como um todo, e não somente como uma junção entre a atividade principal/dominante e a secundária quando se analisa cada um dos estágios do desenvolvimento humano. Nessa perspectiva, Abrantes e Eidt (2019, p. 7) pontuam que "a categoria atividade, enquanto mediadora da relação sujeito - objeto, é o conceito que orienta a análise do desenvolvimento psíquico para o movimento, mesmo concebendo a unidade de contrários entre estabilidade - movimento", sobretudo porque a própria atividade deverá ser compreendida "em seu dinamismo e como relação social viva". Não obstante, complementam que "a categoria atividade participa, em uma mesma relação, em duplo trânsito: do objeto que primariamente dirige a atividade para a atividade como processo social e dessa atividade social particular para a construção do produto subjetivo" (ABRANTES; EIDT, 2019, p. 9).

Quando se analisa as crianças em idade pré-escolar, a atividade principal/dominante refere-se à brincadeira de papéis sociais. Por sua vez, as atividades secundárias que acompanham o desenvolvimento infantil nesse período são aquelas constitutivas ou de produção, ou seja, as atividades 
que abarcam a produção de desenhos, a modelagem, a construção de objetos, o trabalho manual, entre outros (LAZARETTI, 2016).

Neste artigo, o objeto de análise está nas atividades secundárias, com destaque para as experiências artísticas e estéticas, todavia sem desconsiderar a atividade principal que governa $\circ$ desenvolvimento infantil, visto que ambas são essenciais para se refletir sobre o processo tanto do ensino e aprendizagem na formação da personalidade quanto dos processos psíquicos das crianças.

Para que este movimento aconteça, é imprescindível a interação das crianças com os indivíduos mais experientes. Nas instituições formativas, são os/as professores/as e os/as profissionais da educação, os/as quais precisam conhecer o desenvolvimento humano e as características de cada estágio a fim de pensar e (re)pensar as ações realizadas com as crianças em idade pré-escolar e promover um ensino permeado de sentido e significado, através de práticas pedagógicas intencionalmente sistematizadas.

Com esse respaldo, evidenciam-se nas instituições formativas de Educação Infantil algumas práticas pedagógicas que geralmente apresentam vídeos, histórias, músicas, adotados segundo os cânones do capital, isto é, o que a mídia propaga na sociedade (MAGALHÃES, 20I4). Essas escolhas impedem que as crianças ampliem seu repertório e conhecimento acerca do desenvolvimento artístico e estético produzido ao longo da história da humanidade, sobretudo quando se defende e se assume uma perspectiva contra hegemônica àquela institucionalizada pelo Estado.

Destarte, o objetivo do presente artigo é compreender as experiências artísticas e estéticas para a aprendizagem e desenvolvimento das crianças em idade pré-escolar, sendo as ponderações do filósofo húngaro Mészáros (2008, p. 65, grifos do autor) de extrema importância, ao afirmar que:

[...] O papel da educação é soberano, tanto para a elaboração de estratégias apropriadas e adequadas para mudar as condições objetivas de reprodução, como para a automudança consciente dos indivíduos chamados a concretizar a criação de uma ordem social metabólica radicalmente diferente.

Nesse sentido, cabe o questionamento: Como organizar as experiências artísticas e estéticas com intencionalidade e sistematização, de modo a permitir a aprendizagem e o desenvolvimento das crianças em idade pré-escolar?

Para responder tal questionamento, este artigo adota a seguinte organização didática: num primeiro momento, apresentam-se algumas reflexões e possibilidades para a formação do gênero humano, tendo como foco a contextualização do conhecimento artístico, bem como sua relevância para a aprendizagem e desenvolvimento das crianças em idade pré-escolar. Em seguida, são abordados os aspectos da organização do ensino e das práticas pedagógicas com vistas à uma formação sensível, humana e emancipatória. Contempla-se, por fim, reflexões sobre as práticas realizadas nas instituições formativas de Educação Infantil. 
Experiências artísticas e estéticas na aprendizagem e desenvolvimento das crianças em idade pré-escolar...

\section{Reflexões e possibilidades acerca das experiências artísticas e estéticas}

Os seres humanos vivem em um mundo permeado por fenômenos históricos, políticos, econômicos e culturais, os quais influenciam a sua formação, já que "todo homem ao nascer se encontra em um mundo já existente, independentemente dele. Este mundo já se apresenta "constituído" e aqui ele deve conservar-se e dar prova de capacidade vital" (HELLER, 1994, p. 21, tradução autoral).

Por meio do trabalho, os seres humanos produziram e produzem suas condições materiais de vida e satisfazem suas necessidades individuais e coletivas, criando, assim, o próprio ser humano e a humanidade, esta última orientada a partir das leis sócio-históricas. Marx (1983, p. 153) ressalta o papel do trabalho como:

[...] atividade orientada a um fim para produzir valores de uso, apropriação do natural para satisfazer as necessidades humanas, condição universal do metabolismo entre homem e Natureza, condição natural eterna da vida humana e, portanto, independente de qualquer forma dessa vida, sendo antes igualmente comum a todas as suas formas sociais.

Com base nesses aspectos, ao satisfazer suas necessidades, os seres humanos criaram e criam objetos, ou seja, a ação de realizar uma atividade com um fim determinado abarca um ato de consciência. Nesse sentido, os seres humanos, através de suas atividades, convivem e organizam a sociedade coletivamente, conforme o momento histórico circunscrito, produzindo valores de uso (OLIVEIRA, 20I0).

Cumpre ressaltar que esse mundo constituído influencia na formação da consciência, sendo que "[...] não é a consciência que determina a vida, mas é a vida que determina a consciência" (MARX; ENGELS, 1993, p. 5), ou seja, ocorre pela objetividade presente na materialidade humana, via fenômenos históricos, políticos, econômicos e culturais.

Pontua-se que os seres humanos, para realizar suas atividades, precisam "apropriar-se do que outros já criaram”. E é por meio “dessa apropriação e de um 'pôr teleológico' (LUKÁCS, 1978; 198I) determinado para sua atividade que o homem se objetiva" (OLIVEIRA, 20I0, p. 8). Assim, todo objeto criado é sempre um produto social e, ao objetivar esse mundo constituído pelos objetos, criam-se novas necessidades, novos instrumentos e, consequentemente, novos conhecimentos científicos, filosóficos e artísticos, ou seja, a cultura humana.

Isto posto, Oliveira (2010) esclarece que, ao objetivar esse mundo, os seres humanos desenvolvem atividades cotidianas sob a forma de ações para satisfazer necessidades com fins práticoutilitários, ao mesmo tempo que acabam formando "[...] uma consciência em si, isto é, uma consciência que, necessariamente, não tem consciência dessa consciência” (OLIVEIRA, 20I0, p. 8-9, grifos da 
autora). Esta consciência que não conhece a si mesma pode ser chamada de consciência alienada. Destaca-se que o processo de alienação é estabelecido na própria estrutura ontológica do trabalho e, desse modo:

[...] é somente um momento histórico criado pela organização dadas as relações sociais da realidade. E se essa organização é criada pelos homens em determinadas circunstâncias sócio-históricas, é possível que os homens, conhecendo os meandros desse processo, possam interferir nessa realidade para transformá-la (OLIVEIRA, 2010, p. I5).

Há que se ressaltar que, "para Marx, a alienação aparece como uma fase necessária do processo de objetivação, mas uma fase que o homem há de superar, quando se derem as condições necessárias, a fim de que possa desdobrar sua verdadeira essência" (VÁZQUEZ, 20II, p. 130). Tais "condições necessárias" estão nas atividades não cotidianas, tais como a ciência, a filosofia, a arte, o trabalho educativo, entre outros conhecimentos gnosiológicos que desenvolvem uma consciência para si e impactam diretamente na transformação da prática social dos seres humanos (OLIVEIRA, 20I0). Destarte, esse movimento entre atividades cotidianas e não cotidianas acontece de forma dialética, pois trata-se de uma ação que "[...] é indispensável ter-se consciência da consciência, como é o caso do trabalho educativo, estamos concomitantemente tendo uma consciência sem consciência frente a uma série de ações que fazem parte dessa atividade" (OLIVEIRA, 20I0, p. 9).

Em consonância com essa ponderação, as atividades não cotidianas estão interligadas aos atos da consciência. Portanto, é válido o seguinte questionamento: como assegurar experiências artísticas e estéticas com as crianças em idade pré-escolar para o desenvolvimento de uma consciência para si? Para responder a esse questionamento, tem-se clareza que "o trabalho é assim, histórica e socialmente, a condição necessária do aparecimento da arte, bem como da relação estética do homem com seus produtos" (VÁZQUEZ, 1978, p. 73). Nessa perspectiva:

A arte é trabalho do pensamento, mas de um pensamento emocional inteiramente específico [...] a arte parte de determinados sentimentos vitais, mas realiza certa elaboração destes sentimentos [...] que consiste na catarse, transformação destes sentimentos em sentimentos opostos, nas suas soluções (VYGOTSKY, 200I, p. 315).

A arte favorece o momento catártico, ou seja, o encontro do indivíduo com ele mesmo, com aquilo que tem de mais íntimo, seus sentimentos e emoções, ao possibilitar o desenvolvimento das funções psíquicas que são mecanismos intencionais alteradores da consciência e estruturadores do conteúdo do desenvolvimento psicológico, mas antes de se tornarem internas aos seres humanos, elas necessariamente manifestam-se nas relações sociais (VYGOTSKI, 199I).

A humanidade mantém, através da arte, uma experiência tão enorme e excepcional que, comparada com ela, toda experiência de criação doméstica e de conquistas 
Experiências artísticas e estéticas na aprendizagem e desenvolvimento das crianças em idade pré-escolar...

pessoais parece pobre e miserável. Por isso, quando se fala de educação estética dentro do sistema da formação geral, sempre se deve levar em conta, sobretudo, essa incorporação da criança à experiência estética da humanidade (VIGOTSKI, 2003, p. 238).

É necessário considerar, portanto, que as experiências estéticas promovem emoções muito mais complexas que as emoções comuns. Por isso, precisam ser desenvolvidas e aprimoradas de forma planejada desde a infância, uma vez que não são herdadas biologicamente pelos indivíduos (VIGOTSKI, 2003).

Leontiev (1998, p. 29I) esclarece que "quanto mais progride a humanidade, mais rica é a prática sócio-histórica acumulada por ela, mais cresce o papel específico da educação e mais complexa é a sua tarefa" de transmitir direta e indiretamente os conhecimentos acumulados pela humanidade a cada indivíduo singular.

Todavia, parece inequívoco que, neste sistema, parcela expressiva da população e impedida de se apropriar das objetivações humanas mais elaboradas, a exemplo da Arte. Daí a importância dos/as professores buscarem vinculações e estratégias que ultrapassem o estabelecido. Garantir às crianças, filhos/as da classe trabalhadora, o contato com as máximas possibilidades desenvolvidas pela Arte é um ato de resistência que por si só não garantirá a transformação das relações sociais, mas as auxiliarão no processo de compreensão da prática social.

Ao dialogar sobre a Arte e sua função na educação, Lunatcharski (1988) afirma que o desenvolvimento humano é inseparável da Arte e da Educação Estética. Portanto, elas não desenvolvem somente os seres humanos e sua personalidade, mas também, a formação da sociedade e da humanidade. Nas palavras do autor, "[...] uma obra de arte é sempre um reflexo original, isto é, subjetivo, da realidade ou dos fenómenos da consciência humana" (LUNATCHARSKI, 1988, p. 183).

Nesse prisma, as manifestações artísticas não expressam somente um retrato da realidade, são criações que partem da realidade e interligam-se à subjetividade humana. Posto isso, salienta-se a necessidade do desenvolvimento artístico e estético nas crianças ao longo da educação formal, considerando-se a relação entre o indivíduo (singular) e o gênero humano (universal).

Destaca-se que as experiências artísticas e estéticas vivenciadas pelas crianças no ambiente formativo propiciam a criação infantil, a exemplo dos desenhos, da literatura, das artes plásticas, entre outras formas de expressões artísticas essenciais à formação emocional e crítica. Com isso, convém destacar que o papel da Arte "[...] nunca reflete a realidade em toda a sua plenitude e em toda a sua verdade; ela representa sempre um produto sumamente complexo elaborado pelos elementos da realidade, ao qual aporta um conjunto de elementos totalmente alheios" (VIGOTSKI, 2003, p. 228).

Essa assertiva indica que as obras de arte vão muito além da realidade imediata dos seres humanos, elas refletem elementos complexos da sociedade, construídos ao longo da história humana.

Olhar de professor, Ponta Grossa, v. 24, p. I-17, e-17622.079, 2021.

Disponível em <https://revistas2.uepg.br/index.php/olhardeprofessor> 
Nesse sentido, às crianças, ao apropriar-se da realidade objetiva via conhecimentos artísticos, demanda-se um trabalho árduo, uma vez que "a apreciação de uma obra é um trabalho inicialmente difícil e cansativo do psiquismo" (VIGOTSKI, 20I0, p. 332) que perpassa dois estágios. O primeiro é aquele da passividade, cujo foco reside nas características estéticas da obra de arte percebidas pelos organismos por meio dos cincos sentidos: a visão, a audição, ○ olfato, ○ paladar e ○ tato. Dialeticamente, elas funcionam como um impulso básico para que aconteça o segundo estágio, por meio do qual o ser humano torna-se ativo no processo da "segunda síntese criativa" (VIGOTSKI, 2003, p. 304).

Para que o indivíduo seja capaz de realizar essa segunda síntese, ou seja, reunir e sintetizar os elementos artísticos, precisa promover a "[...] atividade estética básica que, por sua natureza, é uma atividade do organismo que reage ao estímulo externo" (VIGOTSKI, 2003, p. 230). Uma vez concluída a segunda síntese, os seres humanos têm a possibilidade de "[...] inserir as reações estéticas na própria vida. A arte transforma a realidade não só em construções da fantasia, mas também na elaboração real das coisas, dos objetos e das situações" (VIGOTSKI, 2003, p. 239).

A partir daí, as reações estéticas envolvem processos qualitativos complexos no psiquismo, transitando entre a imaginação e realidade. Suscitados pela arte, estes processos jamais se repetem, uma vez que estão sempre se modificando dialeticamente na interação entre os indivíduos e a obra de arte. Não obstante, esse processo precisa considerar as características e as mudanças na idade préescolar, visto que "[...] as mudanças na idade no desenvolvimento psíquico e nas características da personalidade não se produzem de maneira tão específica e simultânea ou, para melhor dizer, produzem-se em períodos diferentes, segundo a forma de vida, de atividade e as condições de educação da criança" (BOGOYAVLENSKY; MENCHINSKAYA, 2005, p. 42).

Sob esta perspectiva, convém destacar que no decurso deste processo as crianças estarão constituindo sua personalidade e seus processos psíquicos, sendo que "[...] os processos internos se estruturam, orientando outras ações práticas, mais autônomas e complexas, que enriquecerão os processos internos e assim sucessivamente" (MARTINS, 2006, p. 39). Ou seja, as crianças demonstram em suas atividades como veem o mundo, as relações sociais e humanas, estruturando e aprimorando suas funções psicológicas superiores, a formação da sua personalidade e os seus processos psíquicos que demandam uma interação planejada promovida pelos/as professores/as (MAGALHÃES, 2014).

Visto que as crianças desenvolvem suas atividades a partir das experiências travadas no meio social, o/a professor/a precisa proporcionar às crianças em idade pré-escolar vivências enriquecedoras, levando em consideração a atividade principal e as secundárias, algo que "[...] requer certas formas de ação e exerce sua influência específica no desenvolvimento da criança” (MUKHINA, 1996, p. 167). Não obstante, as atividades necessitam do entrelaçamento entre a realidade e a imaginação. 
Experiências artísticas e estéticas na aprendizagem e desenvolvimento das crianças em idade pré-escolar...

Em relação às atividades secundárias, ou seja, ao desenho, à modelagem, ao recorte, entre outras ações levadas a cabo pelas crianças a fim de atingir um produto final de sua imaginação, estas perpassam suas experiências na realidade social (MUKHINA, 1996). Nesse viés, ressalta-se que, ao desenhar, a criança desenvolve suas funções psicológicas superiores, buscando em suas experiências anteriores os elementos para a constituição de sua manifestação artística. "O desenho infantil sempre é um fato educativamente prazeroso, ainda que às vezes também seja esteticamente feio. Ele sempre ensina a criança a dominar o sistema de suas vivências, a vencê-las e superá-las e, segundo uma excelente expressão, ensina a psique a se elevar" (VIGOTSKI, 2003, p. 236).

O desenho é uma das formas humanas de representação do pensamento. Desenhando, a criança tem a possibilidade de representar a forma como vê o mundo, manifestando assim seus aspectos cognitivos, imaginários e criativos de acordo com o seu desenvolvimento infantil perante a afetividade, o pensamento e a motricidade, pois "entender como a criança desenha, permite entender seu desenvolvimento global" (RIBEIRO, 2019, p. 27).

Oportuno salientar que a atividade criadora da criança depende das experiências anteriores e do contato com os signos presentes em sua realidade objetiva. Tal prerrogativa corrobora a necessidade de ampliar as experiências das crianças a fim de oferecer subsídios eficazes e significativos para o desenvolvimento de sua imaginação e criação. De acordo com Stein (2014, p. 72):

[...] as instituições escolares, quando pautadas por esse princípio teóricometodológico, podem se constituir em espaços de excelência para o desenvolvimento da criação infantil na medida em que articulem às experiências imediatas das crianças com modelos e referências mais complexos de diferentes domínios da atividade humana.

Ao potencializar as experiências artísticas e estéticas, é necessário que os/as professores/as, profissionais da educação, familiares, responsáveis e comunidade externa tenham a consciência de que "a criança não escreve versos nem desenha porque está incubando um futuro criador, mas porque agora isso lhe é necessário [...]” (VIGOTSKI, 2003, p. 236-237). Isto é, ao criar suas manifestações artísticas a partir das experiências e vivências, as crianças intensificam o desenvolvimento de suas funções psíquicas.

A partir disso, é imperioso aos/às professores/as apresentar às crianças o que há de mais elaborado para o aprimoramento das funções psicológicas superiores, pois "[...] as circunstâncias fazem os homens tanto quanto os homens fazem as circunstâncias" (MARX; ENGELS, 1993, p. 36), cabendo à Educação apresentar-se como um processo que permita aos seres humanos desenvolverem suas aptidões e apropriarem-se da cultura historicamente acumulada pela humanidade.

Isso evidencia a relevância do rigor metodológico no desenvolvimento de práticas pedagógicas amparadas na relação conteúdo $X$ destinatário, considerando a dimensão ontológica perante as 
estratégias e recursos capazes de garantir a aprendizagem da Arte e a compreensão estética das crianças.

\section{Aprendizagem e desenvolvimento: organização do ensino em defesa da prática pedagógica intencional e sistematizada}

Ao tratar da aprendizagem e desenvolvimento das experiências artísticas e estéticas, é preciso que se tenha estes conceitos muito bem definidos, sendo que "[...] a aprendizagem escolar nunca parte do zero, toda a aprendizagem da criança na escola tem uma pré-história" (VIGOTSKII, 2016, p. 109), ou seja, antes de adentrar aos espaços escolares, a criança já vivenciou relações sociais na vida cotidiana.

Não obstante, cabe às instituições formativas de Educação Infantil possibilitar a orientação da aprendizagem escolar por meio das práticas pedagógicas intencionais e sistematizadas por parte dos/as professores/as, tendo a clareza de que "[...] o único bom ensino é o que se adianta ao desenvolvimento" (VIGOTSKII, 20I6, p. II4). Em outras palavras, o desenvolvimento não coincide com a aprendizagem.

Para o direcionamento dessas práticas, segundo Leontiev (2016), a atividade precisa conferir um sentido aos indivíduos para que ela se efetue plenamente. Por conseguinte, cabe aos/às professores/as desenvolver práticas pedagógicas que considerem a seguinte premissa, "o fazer humano tem sempre um objetivo - que é alcançado no final do processo, ou seja, o resultado que o sujeito projeta em nível de idéia antes de começar a agir - e um motivo que deflagra sua ação". Dessa forma, “o sentido é dado pela relação entre o motivo e o resultado previsto para a ação" (MELLO, 1999, p. 2I).

Convém destacar que a capacidade criadora das crianças se inicia pelo domínio da fala, aspecto essencial que contribui na organização do pensamento, do sentimento e da forma que veem e percebem o mundo e as relações sociais, permitindo assim a concretização da imaginação criadora que, como já salientado anteriormente, deverá estar atrelada à organização dos processos de ensino de maneira intencional e sistematizada.

Nesse percurso, destaca-se o ponto de partida das crianças, ou seja, o que já conhecem, bem como o ponto de chegada via internalização das funções psicointelectuais essencialmente humanas acerca do conhecimento artístico. Desse modo:

Todas as funções psicointelectuais superiores aparecem duas vezes no decurso do desenvolvimento da criança: a primeira vez, nas atividades coletivas, nas atividades sociais, ou seja, como funções interpsíquicas: a segunda, nas atividades individuais, como propriedades internas do pensamento da criança, ou seja, como funções intrapsíquicas (VIGOTSKII, 2016, p. II4).

Olhar de professor, Ponta Grossa, v. 24, p. I-17, e-17622.079, 2021.

Disponível em <https://revistas2.uepg.br/index.php/olhardeprofessor> 
Experiências artísticas e estéticas na aprendizagem e desenvolvimento das crianças em idade pré-escolar...

Tal dinâmica favorece, inclusive, um repensar sobre o papel das crianças nos espaços escolares, uma vez que "[...] a criança não é apenas o objeto, mas também o sujeito do desenvolvimento. Educação e ambiente não influem automaticamente sobre o desenvolvimento psíquico; tais fatores atuam de maneira diferente segundo o nível de desenvolvimento alcançado pela criança" (BOGOYAVLENSKY; MENCHINSKAYA, 2005, p. 38).

Bogoyavlensky e Menchiskaya (2005, p. 38) reforçam que estes fatores "atuam de maneira diferente segundo o nível de desenvolvimento alcançado pela criança”. Ou seja, trata-se de um processo dependente da interação social, a fim de que se possa desenvolver a complexa capacidade de assimilação do conhecimento.

À luz do exposto, para que as crianças em idade pré-escolar possam desenvolver o psiquismo, elas necessitam de bases sólidas. $O$ mesmo em relação ao conhecimento artístico, pois é somente por meio de aquisição desta base sólida que elas terão a possibilidade de alterar suas criações artísticas, considerando que, "quanto mais a criança viu, ouviu e vivenciou, mais ela sabe e assimilou; quanto maior a quantidade de elementos da realidade de que ela dispõe em sua experiência - sendo as demais circunstâncias as mesmas -, mais significativa e produtiva será a atividade de sua imaginação" (VIGOTSKI, 2009, p. 23).

O desenvolvimento da imaginação está condicionado ao acúmulo de experiências, aos desafios propostos, às possibilidades de organização do ensino e aos procedimentos didáticos. Portanto, a criatividade pode sim ser ensinada, o que enseja ainda mais a necessidade de que as intervenções pedagógicas favoreçam o aprimoramento da capacidade criativa (SACCOMANI, 2014).

Ao observar as práticas pedagógicas nas instituições formativas, pesquisas como a de Magalhães (2014) revelaram que, via de regra, elas apresentam certa incoerência, pois a rotina educativa carece de momentos livres e espontâneos. Um exemplo eloquente é a entrega de desenhos impressos às crianças, solicitando-lhes que realizem a pintura e ou sigam comandos, ou seja, que pintem cada parte do desenho com uma determinada cor. Este tipo de atividade acaba restringindo as experiências artísticas e estéticas nessas ações, por conseguinte, não possibilitam a ampliação do conhecimento para a expressão imaginária e criativa das crianças (STEIN, 20I4).

Mello (1999) reforça que é fulcral a reorganização do ensino de artes pelos/as professores/as e profissionais da educação, de modo a superar as ações rotineiras, repetitivas e mecanizadas junto às crianças. Assim, válidas são as contribuições de Vigotski (2009) ao salientar o seguinte posicionamento:

[...] todo o futuro é alcançado pelo homem com a ajuda da imaginação criadora. A orientação para o futuro, o comportamento que se apoia no futuro e dele procede é a função maior da imaginação, tanto quanto a estrutura educativa fundamental do trabalho pedagógico consiste em direcionar o comportamento do escolar seguindo a linha de sua preparação para o futuro, e o desenvolvimento e o exercício de sua

Olhar de professor, Ponta Grossa, v. 24, p. I-17, e-17622.079, 2021.

Disponível em <https://revistas2.uepg.br/index.php/olhardeprofessor> 
imaginação são uma das principais forças no processo de realização desse objetivo (VIGOTSKI, 2009, p. 122).

Para tanto, há que se garantir processos de formação inicial e continuada de professores/as que desmitifiquem o assistencialismo, os atos pejorativos e as práticas pedagógicas conforme os cânones do capital, numa perspectiva contra-hegemônica, assegurando as possibilidades concretas para se ampliar e ensinar o saber historicamente elaborado pelos seres humanos (SAVIANI, 20I3).

Nesse sentido, as ações do trabalho educativo "[...] expressam os fundamentos teóricometodológicos constituídos pelos profissionais ao longo do processo ocorrido tanto na formação inicial quanto na continuada" (SAITO; OLIVEIRA, 20I8, p. 2). Isto posto, é mister reforçar a necessidade dos/as professores/as terem bases sólidas para propiciar processos de ensino e aprendizagem junto aos/às alunos/as.

Reconhecendo os/as professores/as como "[...] mestres que devem ser os trilhos por onde se movimentam com liberdade e independência os vagões, que recebem deles apenas a orientação do próprio movimento" (VYGOTSKY, 200I, p. 64), complementa-se que todo ato educativo expressa uma dimensão teleológica, ou seja, uma forma de se ver o mundo e as relações humanas, bem como o lugar onde se pretende chegar.

Assim, há um grande desafio a ser superado na organização da rotina pedagógica das crianças levando em consideração as dimensões gnosiológicas (quais conhecimentos adotar) e ontológica, de modo a respeitar suas necessidades, tendo clareza dos objetivos a serem alcançados no processo de ensino e aprendizagem com vistas à formação de seres humanos sensíveis e emancipados perante a realidade em que estão inseridos. Nessa acepção, não há aprendizagem e desenvolvimento da consciência no indivíduo singular sem a retomada do conhecimento para uma linguagem artística que favoreça a releitura de seus valores sociais e emocionais, por meio da e na superação dos fragmentos do senso comum (SAVIANI, 20I3).

Portanto, há que se garantir uma reformulação do trabalho educativo desenvolvido com as crianças em idade pré-escolar a fim de se oferecer um ensino permeado de sentido e significado, com intervenções pedagógicas condizentes, inclusive com o seu desenvolvimento e em consonância com as problemáticas que emanam da prática social.

\section{Considerações Finais}

As experiências artísticas e estéticas nas instituições formativas de Educação Infantil possibilitam a aprendizagem e o desenvolvimento das crianças em idade pré-escolar, todavia precisam ser planejadas com intencionalidades e sistematizações a fim de assegurar a formação de crianças sensíveis, humanas e emancipadas. 
Experiências artísticas e estéticas na aprendizagem e desenvolvimento das crianças em idade pré-escolar...

À luz do exposto, defende-se que as manifestações artísticas favorecem a criação, a imaginação e a criatividade, demandando um desenvolvimento através de intervenções pedagógicas que não apresentem às crianças o que o capital difunde, mas, inversamente, permitam o desenvolvimento das funções psicológicas superiores por meio da capacidade criativa das crianças. Essas intervenções pedagógicas precisam partir de suas inquietações e motivações, de modo que elas compreendam o porquê de estarem realizando determinada atividade.

Diante disso, retoma-se o questionamento feito na introdução deste artigo: Como organizar as experiências artísticas e estéticas com uma intencionalidade e uma sistematização que permitam a aprendizagem e o desenvolvimento das crianças em idade pré-escolar? Somente por meio de um diálogo com a literatura científica, pautado na relação dialética entre as perspectivas teóricas da pedagogia histórico-crítica e da psicologia histórico-cultural, será possível reafirmar o papel dos estudos de autores/as clássicos e contemporâneos na defesa de um processo de ensino e aprendizagem rico de sentido e significado nas instituições formativas de Educação Infantil.

\section{Referências}

ABRANTES, A. A.; EIDT, N. Psicologia histórico-cultural e a atividade dominante como mediação que forma e se transforma: contradições e crises na periodização do desenvolvimento psíquico. Obutchénie: Revista de Didática e Psicologia Pedagógica, Uberlândia, v. 3, n. 3, p. I-36, set./dez. 2019. DOI: https://doi.org/I0.14393/OBv3n3.a2019-51694

BOGOYAVLENSKY, D. N.; MENCHINSKAYA, N. A. Relação entre aprendizagem e desenvolvimento psicointelectual da criança em idade escolar. In LURIA; LEONTIEV; VYGOTSKY; outros. Psicologia e pedagogia: bases psicológicas da aprendizagem e do desenvolvimento. São Paulo, SP: Centauro, 2005. p. 63-85.

BRASIL. Lei de Diretrizes e Bases da Educação Nacional. Lei número 9394, 20 de dezembro de 1996. Estabelece as diretrizes e bases da educação nacional. Disponível em: https://www2.senado.leg.br/bdsf/bitstream/handle/id/529732/lei_de_diretrizes_e_bases_led.pdf. Acesso em: 13 mar. 2020.

BRASIL. Lei $\mathbf{n}^{\circ}$. 1 0.172, de 9 de janeiro de 200I. Aprova o Plano Nacional de Educação e dá outras providências (200I/20I0). Disponível em: www.planalto.gov.br/ccivil_03/leis/L8069.htm. Acesso em: 22 dez. 2020.

BRASIL. Lei $\mathbf{n}^{\circ}$. I I.I I 4, de 9 de maio de 2005. Altera os arts. $6^{\circ}, 30,32$ e 87 da Lei $n^{\circ} .9 .394$, de 20 de dezembro de 1996, com o objetivo de tornar obrigatório o início do ensino fundamental aos seis anos de idade. Disponível em: http://www.planalto.gov.br/ccivil_03/_Ato2004-

2006/2005/Lei/LIIII 4.htm. Acesso em: 02 de jan. de 202I.

BRASIL. Lei $\mathbf{n}^{\circ}$. I I.274, de 6 de fevereiro de 2006. Altera a redação dos arts. 29, 30, 32 e 87 da Lei $n^{\circ} .9 .394$ de 20 de dezembro de 1996, dispondo sobre a duração de 9 (nove) anos para o ensino fundamental, com matrícula obrigatória a partir dos 6 (seis) anos de idade. Disponível em: http://www.planalto.gov.br/ccivil_03/_Ato2004-2006/2006/Lei/LI I274.htm. Acesso em: 02 de jan. de 2021.

Olhar de professor, Ponta Grossa, v. 24, p. I-17, e-17622.079, 2021.

Disponível em <https://revistas2.uepg.br/index.php/olhardeprofessor> 
BRASIL. Lei $\mathbf{n}^{\circ}$. I 2.796, de 4 de abril de 20I3. Altera a Lei $n^{\circ}$ 9.394, de 20 de dezembro de 1996, que estabelece as diretrizes e bases da educação nacional para dispor sobre a formação dos profissionais da educação e dar outras providências. Disponível em: http://www.planalto.gov.br/ccivil_03/_Ato20I I-2014/2013/Lei/LI2796.htm. Acesso em: 04 de jan. de 2021.

GIL, A. C. Métodos e técnicas de pesquisa social. 6. ed. São Paulo: Atlas, 2002.

HELLER, A. Sociología de la vida cotidiana. 4. ed. Barcelona: Ediciones Península, 1994.

LAZARETTI, L. M. Idade pré-escolar (3-6 anos) e a educação infantil: a brincadeira de papéis sociais e o ensino sistematizado. In: MARTINS, L. M.; ABRANTES, A. A.; FACCI, M. G. D. Periodização histórico-cultural do desenvolvimento psíquico: do nascimento à velhice. Campinas, SP: Autores Associados, 2016. p. 129-147.

LEONTIEV, A. N. O homem e a cultura. In: LEONTIEV, A. N. O desenvolvimento do psiquismo. São Paulo: Editora Moraes, 1998. p. 277-302.

LEONTIEV, A. N. Uma contribuição à Teoria do Desenvolvimento da Psique Infantil. In: VIGOTSKII, L. S.; LURIA, A. R.; LEONTIEV, A. Linguagem, desenvolvimento e aprendizagem. São Paulo, SP: Ícone, 2016. p. 59-83.

LUKÁCS, G. Introdução a uma estética marxista. Rio de Janeiro: Civilização Brasileira, 1978.

LUKÁCS, G. Ontologia dell'essere sociale. Roma: Riuniti, v. II, I98I.

LUNATCHARSKI, A. V. Artigos e discursos sobre a instrução e a educação. Moscou: Edições Progresso, 1988.

MAGALHÃES, Cassiana. Implicações da teoria histórico-cultural no processo de formação de professores da educação infantil. 20I4. 196 f. Tese (doutorado) - Universidade Estadual Paulista, Faculdade de Filosofia e Ciências de Marília, 2014. Disponível em:

https://repositorio.unesp.br/bitstream/handle/ I I 449// 10468/000794088.pdf?sequence= I \&isAllowed= y. Acesso em: 02 fev. 2021.

MARTINS, L. M. A brincadeira de papéis sociais e a formação da personalidade. In: ARCE, A.;

DUARTE N. Brincadeira de papéis sociais na educação infantil: como contribuições de Vigotski, Leontiev e Elkonin. São Paulo, SP: Xamã, 2006. p. 27-50.

MARTINS, L. M., ARCE, A. A Educação Infantil e o Ensino Fundamental de Nove Anos. In.: ARCE, A; MARTINS, L.M. (Orgs). Quem tem medo de ensinar na educação infantil? em defesa do ato de ensinar. Campinas, SP: Editora Alínea, 2010, p. 39-66.

MARX, K.; ENGELS, F. A ideologia alemã. São Paulo: Hucitec, 1993.

MARX, K. O Capital. Tradução: Regis Barbosa e Flávio R. Kothe. São Paulo: Abril Cultural, 1983.

(Coleção “Os Economistas”, v. I).

MELLO, S. A. Algumas implicações pedagógicas da Escola de Vygotsky para a educação infantil. Próposições, Campinas-SP, v. 10, n. I, 1999, p. 16-27. Disponível em:

https://periodicos.sbu.unicamp.br/ojs/index.php/proposic/article/view/8644097. Acesso em: 07 de jan. de 2021 . 
Experiências artísticas e estéticas na aprendizagem e desenvolvimento das crianças em idade pré-escolar...

MÉSZÁROS, I. A educação para além do capital. São Paulo, SP: Boitempo, 2008.

MORI, N. N. R. Metodologia da pesquisa. Maringá, PR: Eduem, 2016.

MUKHINA, V. Psicologia da idade pré-escolar: um manual completo para compreender e ensinar a criança desde o nascimento até os setes anos. São Paulo: Martins Fontes, 1996.

OLIVEIRA, B. A. de. Fundamentos filosóficos marxistas da obra vigotskiana: a questão da categoria de atividade e algumas implicações para o trabalho educativo. In MENDONÇA, S. G. de L.; MILLER., S. Vigotski e a escola atual: fundamentos teóricos e implicações pedagógicas. Marília-SP: Cultura Acadêmica, 2010. p. 03-26.

RIBEIRO, P. H. Possibilidades com o desenho para aprendizagem da linguagem escrita: contribuições da teoria histórico-cultural. 2019. 7l f. Trabalho de Conclusão de Curso (Graduação em Pedagogia) - Universidade Estadual de Maringá, Maringá, 2019. Disponível em:

http://www.dfe.uem.br/poliana_hreczynski_ribeiro.pdf. Acesso em: 20 de jan. de 202I.

SACCOMANI, M. C. da S. A criatividade na arte e na educação escolar: uma contribuição à pedagogia histórico-crítica à luz de Georg Lukács e Lev Vigotski. 20I4. 186 f. Dissertação (Mestrado em Educação Escolar). Universidade Estadual Paulista "Júlio de Mesquita Filho", Faculdade de Ciências e Letras (Campus de Araraquara), 2014. Disponível em:

https://repositorio.unesp.br/bitstream/handle/I I 449// I5679/000809776.pdf?sequence= I \&isAllowed= y. Acesso em: 20 de jan. de 2021 .

SAITO, H. T. I.; OLIVEIRA, M. R. F. de. Trabalho docente na educação infantil: olhares reflexivos para a ação intencional e planejada do ensino. Imagens da Educação, Maringá-PR, v. 8, n. I, 2018, p. II5. DOI: https://doi.org/I0.4025/imagenseduc.v8il.393I0.

SAVIANI, D. Educação: do senso comum à consciência filosófica. 19 ed. Campinas, SP: Autores Associados, 2013.

STEIN, V. A Educação estética: contribuições dos estudos de Vigotski para o ensino de arte na educação infantil. 20I4. 108 f. Dissertação (Mestrado em Educação) - Universidade Estadual de Maringá, Maringá, 20I4. Disponível em: http://www.ppe.uem.br/dissertacoes/2014\%20\%20Vinicius\%20Stein.pdf. Acesso em: 20 de jan. de 202I.

VÁZQUEZ, A. S. A concepção da práxis em Marx. In: VÁZQUEZ, A. S. Filosofia da práxis. São Paulo: Expressão Popular, 20II. p. III-172.

VÁZQUEZ, A. S. Sobre as idéias estéticas de Marx e os problemas de uma estética marxista. In: VÁZQUEZ, A. S. As idéias estéticas de Marx. Rio de Janeiro: Editara Paz e Terra S.A., 1978. p. 5166.

VIGOTSKII, L. S. Aprendizagem e desenvolvimento intelectual na idade escolar. In: VIGOTSKII, L. S.; LURIA, A. R.; LEONTIEV, A. N. Linguagem, desenvolvimento e linguagem. São Paulo: Ícone, 2016. p. 103-118.

VIGOTSKI, L. S. Imaginação e criação na infância. São Paulo, SP: Ática, 2009.

VIGOTSKI, L. S. Psicologia pedagógica. Porto Alegre, RS: Artmed, 2003.

VIGOTSKI, L. S. Psicologia pedagógica. São Paulo, SP: Martins Fontes, 2010.

Olhar de professor, Ponta Grossa, v. 24, p. I-17, e-17622.079, 2021.

Disponível em <https://revistas2.uepg.br/index.php/olhardeprofessor> 
VYGOTSKI, L. S. Obras Escogidas. Tomo III. Madrid: Aprendizaje Visor y Ministerio de Educación y Ciencia, 1991.

VYGOTSKY, L. S. Psicologia da arte. São Paulo, SP: Martins Fontes, $200 \mathrm{I}$.

Recebido em: I4 de março de 2021 .

Versão corrigida recebida em: 24 de maio de 2021 .

Aceito em: 28 de julho de 2021 .

Publicado online em: 03 de setembro de 2021.

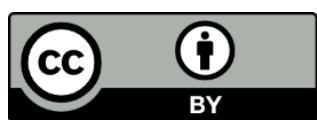

